\title{
Uma leitura walloniana do movimento: crianças de seis anos no ensino fundamental
}

\author{
Fátima Bissoto Medeiros Cintra \\ Prefeitura Municipal de São Paulo - São Paulo-SP - Brasil \\ Laurinda Ramalho Almeida \\ Pontifícia Universidade Católica de São Paulo - São Paulo -SP - Brasil
}

\begin{abstract}
Resumo
Este artigo refere-se a uma investigação que teve como objetivo compreender como estava sendo tratada a motricidade das crianças de seis anos que, com a implantação do ensino de nove anos, passaram a frequentar o ensino fundamental. O referente teórico foi a psicogenética de Henri Wallon; então, apesar de ter focado a motricidade, não se perdeu de vista sua indissociabilidade da cognição e da afetividade. Foram observadas duas turmas de $1^{\circ}$ ano de uma escola municipal da Zona Oeste de São Paulo. As sessões de observação, registradas em diário de campo, foram sintetizadas em episódios. O estudo apontou que a escola ainda não reconhece a importância do ato motor para o desenvolvimento cognitivo e afetivo, oferece poucas oportunidades para que as crianças de seis anos vivenciem o espaço físico - fundamental para a construção do espaço mental - e poucos momentos para brincadeiras de ficção - importantes para o fortalecimento da representação.
\end{abstract}

Palavras-chave: Processo motor; crianças; ensino fundamental.

\section{A wallonian movement reading: six-year children in fundamental education}

\begin{abstract}
This article refers to an investigation that aimed to understand how the motricity of 6-year-old children was treated, who, with the implementation of nine-year education, started attending elementary school. The theoretical reference was Henri Wallon'spsychogenetics, so although he focused his motor skills, he did not lose sight of his inseparability of cognition and affectivity. Two classes of the first year of a municipal school of the West Zone of São Paulo were observed. The observation sessions, recorded in the field diary were synthesized in episodes. The study pointed out that the school still does not recognize the importance of the motor act for cognitive and affective development it offers few opportunities for six year old children to experience the physical space - fundamental for the construction of the mental space - and few moments for games of Fiction important for the strengthening of representation.
\end{abstract}

Keywords: Motor process; Children; elementary School.

\section{Una lectura walloniana del movimiento: niños de seis años en la enseñanza primaria}

\section{Resumen}

Este artículo se refiere a una investigación que tuvo como objetivo comprender como estaba siendo tratada la motricidad de los niños de seis años que, con la implantación de la enseñanza de nueve años, pasaron a frecuentar la enseñanza primaria. El referente teórico fue la psicogenética de Henri Wallon, entonces a pesar de tener enfocado la motricidad, no se perdió de vista su insociabilidad de la cognición y de la afectividad. Se observaron dos grupos de $1^{\text {er }}$ año de una escuela municipal de la Zona Oeste de São Paulo. Las sesiones de observación, registradas en diario de campo, se sintetizaron en episodios. El estudio apuntó que la escuela aun no reconoce la relevancia del acto motor para el desarrollo cognitivo y afectivo, ofrece pocas oportunidades para que los niños de seis años vivencien el espacio físico - fundamental para la construcción del espacio mental - y pocos momentos para juegos de ficción - importantes para el fortalecimiento de la representación.

Palabras clave: Procesos motores; niños; enseñanza primaria. 


\section{Introdução}

A aprovação da Lei 11.274, de 6 de fevereiro de 2006 ampliou a duração do ensino fundamental para nove anos e teve o ano de 2010 como prazo limite para sua implantação. Com isso, as escolas da rede municipal de São Paulo passaram a receber crianças de seis anos que apresentavam características diferentes das de sete, especialmente menor capacidade de concentração e maior necessidade de movimento. Tais características levaram a reflexões sobre as dimensões da atuação do professor: o ensino de conteúdos e a gestão da classe. É fundamental para o sucesso do processo de ensino e aprendizagem que haja um equilíbrio entre essas duas dimensões e que o professor crie uma ordem, de modo a tornar a sala de aula um espaço de aprendizagem. Gauthier e Martineau (2001, p. 59) defendem que é necessária "certa forma de ordem funcional, a fim de que, no contexto de um trabalho coletivo como o da sala de aula, as aprendizagens (no sentido de instrução e de educação) possam ser realizadas". Assim, cabe ao professor, por um lado, oferecer um ensino eficiente que possibilite a aprendizagem e, por outro lado, propiciar um ambiente favorável para que ocorra a aprendizagem, introduzindo regras e rotinas de trabalho.

Saber equilibrar a gestão de conteúdos e a gestão da classe é uma arte e um desafio, especialmente para o professor do $1^{\circ}$ ano. Como ensinar crianças que ainda não são capazes de se concentrar por longos períodos de tempo e precisam se movimentar? Considerando que essas sejam características da fase de desenvolvimento em que se encontram, de que forma a escola pode lidar com essa questão, compreendendo e, ao mesmo tempo, contribuindo para que elas avancem no seu desenvolvimento? Tais preocupações nos levaram a realizar uma pesquisa cujo objetivo foi compreender como estava sendo tratada a motricidade das crianças de seis anos que ingressavam no ensino fundamental.

\section{Fundamentação teórica}

A teoria psicogenética de Henri Wallon oferece suporte teórico para compreender a dimensão motora como constituinte da pessoa, pois tem como um dos pontos principais a integração dos domínios afetivo, cognitivo e motor. "É uma teoria que facilita compreender o indivíduo em sua totalidade, que indica as relações que dão origem a essa totalidade, mostrando uma visão integrada da pessoa do aluno" (Mahoney, 2009, p. 9).

Apesar de a dimensão motora ser o tema desta pesquisa, vale ressaltar que ela é indissociável das dimensões afetiva e cognitiva. "É contrário à natureza tratar a criança fragmentariamente. Em cada idade, ela é um todo indissociável e original" (Wallon, 1941/2007, p. 198).

A psicologia genética é, de acordo com Wallon (1956/1975e, p. 53), aquela "que define o psiquismo na sua formação e nas suas transformações". Em escala individual, estuda a transformação da criança em adulto. A psicogênese está ligada a duas espécies de condições: uma orgânica e outra relativa ao meio. A maturação do sistema nervoso precisa estar aliada a uma diversidade de atividades proporcionadas pelo meio, tanto humano como físico, para que possa levar à evolução funcional.

Os pontos principais da psicogenética de Wallon são a integração entre organismo e meio e a integração entre os conjuntos funcionais: afetividade, cognição, ato motor e pessoa. Esse último conjunto é considerado por Wallon como o quarto conjunto funcional, que não apenas garante a integração entre os outros três, mas também é o resultado dessa integração.

Os conjuntos funcionais são constructos utilizados para explicar o psiquismo. Inicialmente, eles aparecem de forma sincrética; depois, paulatinamente, vão se diferenciando e respondendo de forma mais precisa às solicitações do meio.

A afetividade refere-se a sensações de tonalidades agradáveis ou desagradáveis provocadas por fenômenos internos ou externos. Ela tem origem nas sensações viscerais e musculares e na sensibilidade vinda do meio físico e, principalmente, do meio social. Segundo Almeida (2010, p. 26),"das oscilações musculares e viscerais vão se diferenciando as emoções: medo, alegria, raiva, ciúme, tristeza. Pelo seu poder plástico, expressivo e contagioso, a emoção estabelece os primeiros laços com o mundo humano e, através dele, com o mundo físico".

A cognição, por sua vez, possibilita à pessoa a aquisição de conhecimentos sobre si mesma e sobre o mundo. Também está relacionada à aquisição e ao uso da linguagem, à memória, ao planejamento de ações futuras, à imaginação, à aprendizagem eà resolução de problemas. De acordo com Mahoney (2009), no início, as informações fornecidas pelo meio apresentam-se de forma confusa, sem relação entre elas; todavia, ao tomar consciência de si, elas tendem a transformar-se em conceitos claramente relacionados, ou seja, em categorias.

Para Wallon (1956/1975b), o ato motor é responsável pelos deslocamentos do corpo e por seu equilíbrio. No início, os movimentos são sincréticos e, posteriormente, tornam-se controlados e ajustados às situações apresentadas pelo meio. Com o aperfeiçoamento dos movimentos, a criança vai percebendo as relações entre cada parte de seu corpo e entre os objetos que a circundam. O movimento apresenta três formas: passivo ou exógeno, ativo ou autógeno e movimento das reações posturais. Todas as três têm sua importância na evolução do psiquismo infantil e condicionam-se mutuamente, podendo combinar-se de diferentes formas e com diferentes graduações, variando de pessoa para pessoa.

O movimento passivo ou exógeno refere-se aos deslocamentos que possibilitam ao corpo atingir seu equilíbrio, enquanto o movimento ativo ou autógeno refere-se aos deslocamentos intencionais do corpo, ou de partes dele, no tempo e no espaço. Já o movimento das reações posturais caracteriza-se por mímicas ou expressões corporais e faciais. Esse tipo de movimento tem origem na variação das 
emoções, e seus deslocamentos são pouco perceptíveis, pois ocorrem na plástica da musculatura, não envolvendo mudanças corporais no tempo e no espaço.

Seja em sua forma exógena, autógena ou postural, o movimento procede da atividade muscular. A musculatura, por sua vez, apresenta duas funções: cinética (ou clônica) e tônica. A função cinética permite a realização de movimentos voluntários. Já a função tônica apresenta-se sob duas formas: uma que mantém os músculos na forma presente, dando consistência (tônus contrátil), outra que produz a mímica corporal ou as atitudes (tônus plástico). Nos movimentos que realizamos, estão presentes ambas as funções, apesar de a cinética ser a mais visível.

O indivíduo não nasce com todo o aparato de reflexos e percepções que, combinados, explicariam seu desenvolvimento. À medida que cresce, partes de seu sistema nervoso vão sendo ativadas. A maturação orgânica é indispensável para a evolução funcional, pois vai acrescentando possibilidades ao material já existente.

A motricidade ocupa um lugar de destaque na psicogenética walloniana. Desde o nascimento, a motricidade é uma dasformas mais ricas de interação com o meio externo e um instrumento de comunicação da vida psíquica. Além disso, a motricidade é a forma utilizada pelo bebê para interagir - interação essa que, inicialmente, se dá com os outros, estendendo-se, posteriormente, aos objetos.

No recém-nascido, os movimentos são simples descargas motoras, sobre as quais ele não tem controle e cuja utilidade é satisfazer suas necessidades básicas. Ele depende do outro, geralmente a mãe, para alimentá-lo, mantê-lo limpo e aquecido, trocá-lo de posição etc. Os atos do bebê expressam seu desconforto e afetam o outro, que se mobiliza para eliminar tal desconforto. Dessa forma, a criança vai estabelecendo uma comunicação com o meio humano que, aliada à maturação, provocará grandes progressos em sua evolução.

A primeira relação entre movimento e percepção ocorre no espaço bucal. O bebê leva tudo à boca. Após o primeiro semestre de vida, desenvolvem-se relações mais diversificadas entre percepção e movimento, a partir do estabelecimento de conexões entre diferentes campos sensoriais, uma vez que as mudanças provocadas pelo movimento são percebidas por vários deles simultaneamente. Entretanto, para que esta simultaneidade seja reconhecida, deve haver certo grau de maturação funcional (Wallon, 1941/2007).

Inicialmente, o bebê realiza, de modo casual, um movimento que produz um efeito que lhe agrada. Busca, então, repetir o movimento, com a intenção de reproduzir o mesmo efeito. Essas atividades são conhecidas como reações circulares. Nelas, a sensação suscita o gesto apropriado para reproduzi-la, primeiramente para que possa ser reconhecida e, posteriormente, para modificá-la. Essa associação entre os campos sensoriais e musculares só é possível com a maturação neurológica que envolve esses diferentes campos e que permite a coordenação da cabeça, dos olhos e da mão.
O período correspondente ao primeiro ano de vida consiste, essencialmente, na preparação das condições sensório-motoras que possibilitarão a exploração intensa do ambiente durante o segundo ano de vida. Antes de andar, o espaço da criança limita-se ao comprimento do seu braço. Com a aquisição da marcha, ela passa a explorar o ambiente, locomovendo-se por si própria.

À medida que vai estabelecendo relações diversificadas com o meio físico, a criança desenvolve uma inteligência prática ou inteligência das situações. É capaz de resolver situações utilizando os recursos disponibilizados pelo ambiente.

A aquisição da fala também contribui para o desenvolvimento da inteligência prática. Sendo capaz de nomear e localizar os objetos, a criança pode compará-los e agrupá-los. Assim, a marcha e a fala introduzem-na ao mundo simbólico; entretanto, como o pensamento ainda é incipiente, ela necessita do auxílio de gestos para expressá-lo. A criança "parece querer representar por gestos o seu pensamento que facilmente fraqueja e distribuir as imagens à sua volta, como que para assim Ihes conferir uma espécie de presença" (Wallon, 1956/1975b, p. 80).

Contrapondo-se à inteligência das situações, temos a inteligência discursiva, que opera com representações. Seria possível acreditar que esta fosse uma continuidade da primeira,porém, nenhuma pessoa, pode por si só, atingir esse nível simbólico, pois "alinguagem enunciada ou interior que forma uma só coisa com o pensamento discursivo, bem como as relações e as representações de que ela é suporte, têm como matriz indispensável a sociedade" (Wallon, 1942/2008, p. 20).

Apesar de fundamental para o surgimento da inteligência discursiva, não é a linguagem que prepara a passagem da inteligência prática para a discursiva, mas sim a imitação. A imitação é movimento, muito mais voltado para a atividade em si mesma do que para o mundo exterior, "que tem por meios e objetivos as próprias atitudes do sujeito, e que é ao mesmo tempo acomodação às atividades do outro. Em seus princípios e em si mesma, a imitação é atividade plástica" (Zazzo, 1975/1976, p. 47, tradução nossa).

Diferentemente dos gestos de repetição, a imitação não é imediata, ela necessita de um tempo entre a percepção e a execução. Ao assistir a um espetáculo que a interesse, a criança, segundo Wallon (1942/2008), fica em "estado de impregnação perceptivo-motora". A musculatura da criança está trabalhando, apesar de, muitas vezes, apresentar contrações imperceptíveis. Somente após um período de incubação, que pode variar de minutos a semanas, é que a criança reproduzirá os movimentos observados.

$\mathrm{Na}$ imitação coexistem automatismo e invenção. Para captar as impressões causadas pelo modelo e exteriorizá-las em gestos, a imitação busca, no repertório de automatismos da pessoa, aqueles que, em face do modelo, servem à sua interiorização e, sucessivamente, à sua exteriorização. A imitação, então, necessita não só discriminar e selecionar os gestos para copiar o modelo, como também, ao reproduzi-los, distribuí-los no espaço e no tempo. Esse 
processo exige tanto automatismo como invenção, e entre ambos existe um antagonismo. A invenção tenta superar o automatismo ao transformar atitudes e posturas em expressões afetivas e, assim, separar-se do objeto que tenta imitar (Wallon, 1941/2007).

Após esse período de imitação espontânea, segue-se o de imitação eletiva, no qual a criança passa a imitar as pessoas que admira. Guillaume (1950/1975, p. 231, tradução nossa) alerta que nem sempre a criança "imita aqueles que são superiores a ela, no verdadeiro sentido da palavra, é que a seus olhos seus modelos têm uma espécie de prestígio muito difícil de ser definido por outros".Por não possuir uma imagem objetiva do modelo, a criança ainda não é capaz de se opor a ele, então, inicialmente, funde-se a ele, alienando-se de si própria. Depois, segue-se o desejo de substituir o modelo, já que, segundo Wallon(1942/2008, p. 149),"é querendo ser semelhante ao modelo que a criança se contrapõe à pessoa e deve justamente acabar distinguindo-se também do modelo". A partir dos seis anos, a imitação torna-se racional e os interesses imediatos, gradualmente, vão dando lugar aos interesses diferidos.

Entre a imitação e a representação podemos situar o simulacro, isto é, "um ato sem objeto real, embora à imagem de um ato verdadeiro" (Wallon, 1941/2007, p. 151). Essa atividade, que envolve movimento e representação, desenvolve-se amplamente na criança por meio das brincadeiras ficcionais ou de faz de conta. O simulacro é um prelúdio à representação.

Como foi apontado anteriormente, é por meio da imitação que se dá a passagem da inteligência prática para a inteligência discursiva; entretanto, para que isso aconteça, é preciso algo comum entre elas, que, no caso, é o espaço. Esse espaço é, ao mesmo tempo, comum e distinto. À inteligência das situações corresponde o espaço motor e à inteligência discursiva corresponde o espaço mental. Tran-Thong (1967/1987, p. 203) explica que tais espaços diferenciam-se "pela sua natureza, o seu plano e o seu modo de elaboração, mas possuem como condição comum o espaço real”.

O espaço motor possui níveis. Primeiramente, o espaço bucal: o bebê leva os objetos à boca e, assim, combinando movimento e sensação, vai identificando suas características. Quando passa a ter certo domínio dos membros superiores, podendo agarrar o que suas mãos alcançam, apossa-se do espaço circundante. Quando finalmente é capaz de locomover-se para onde desejar e expressar-se por meio da linguagem, os objetos adquirem maior independência e realidade.

A passagem da atividade psicomotora para a atividade mental parece acontecer no momento em que a noção de espaço, deixando de confundir-se com o espaço do movimento e do corpo, passa a referir-se a relações exteriores e independentes da pessoa. É a conquista do espaço objetivo, isto é, "o espaço onde o sujeito pode contrapor a si mesmo o mundo exterior e que ele pode transformar em ponto de partida para seu conhecimento das coisas" (Wallon, 1942/2008, p. 201).
Na inteligência prática, a intuição espacial está implicada nos movimentos a executar. A criança não percebe relação entre os objetos, ela os integra a seus movimentos, como um prolongamento de si, a fim de obter o resultado desejado. Diferentemente do espaço motor, o espaço mental é abstrato e independe dos movimentos e do corpo, porém só pode se constituir com a maturação da aptidão simbólica.

Com a maturação orgânica, que ocorre por volta dos seis anos de idade, começa a se desenvolver uma nova capacidade: a atenção voluntária, denominada por Wallon(1941/2007) de autodisciplina mental, que permite à criança permanecer mais tempo em uma mesma atividade, desconsiderando os estímulos externos que não estejam ligados àquela atividade. A criança já é capaz de desligar-se de uma tarefa espontânea para executar uma tarefa proposta, adiando seu desejo imediato e subjetivo.

Pelo fato de a maturação neurológica ainda não haver se concretizado plenamente, a criança apresenta comportamentos instáveis: ora concentra-se em uma atividade da qual não consegue se desligar (perseveração), ora volta-se para todo e qualquer estímulo externo que surge (instabilidade mental). Para o estabelecimento da autodisciplina mental, é necessário que, além da maturação neurológica, haja a aquisição de instrumentos simbólicos, o que se dá por meio da aprendizagem.

\section{A psicogênese e a integração com o meio}

Para Wallon, o estudo da criança exige o estudo do(s) meio(s) em que ela se desenvolve. A psicogênese está intimamente ligada às relações com o meio, tanto humano como físico. A visão walloniana de meio não é determinista, muito pelo contrário, é dialética. Segundo ele, "a constituição biológica da criança, ao nascer, não será a única lei do seu futuro destino. Os seus efeitos podem ser amplamente transformados pelas circunstâncias sociais da sua existência, donde a escolha pessoal não está ausente" (Wallon, 1954/1975c, p. 165).

Wallon distingue meios de grupos. Apesar de às vezes coincidirem, suas noções são distintas, pois, para ele, "o meio não é outra coisa senão o conjunto mais ou menos duradouro das circunstâncias onde se desenrolam existências individuais"(Wallon, 1954/1975c, p. 165). Esse meio engloba os aspectos físicos e naturais que são transformados pelo grupo humano; contudo, o espaço não é o fator mais importante na determinação do meio. Existem meios funcionais que podem ou não coincidir com os locais. Para Wallon (1954/1975c, p. 166), o que interessa, sobretudo, "é a semeIhança dos interesses, das obrigações, dos costumes".

A escola, por exemplo, é um meio funcional, pois as crianças a frequentam com o objetivo comum de se instruírem e de se familiarizarem com um novo tipo de relações interpessoais; ao mesmo tempo, é um meio local, no qual crianças de diferentes meios sociais se encontram. A família, além de ser um meio funcional, no qual a criança encontra recursos para satisfazer suas necessidades e adquire as 
primeiras noções de conduta social, possui uma estrutura que a torna um grupo. Éo primeiro grupo instituído, que tem como função satisfazer a criança em suas necessidades básicas e garantir-lhe a primeira educação.

No grupo, há uma definição clara de papéis e as relações são determinadas. Wallon (1954/1975c) exemplifica essa situação com os papéis definidos nas relações familiares: o papel da criança na constelação familiar (filho caçula, do meio, mais velho ou único) é que irá determinar as relações com os outros membros do grupo.

O grupo é fundamental para as várias aprendizagens da criança-cognitiva, afetiva e psicomotora -e apresenta- Ihe duas exigências opostas. Por um lado, a criança precisa identificar-se com os objetivos e interesses do grupo; por outro, precisa assumir seu papel no grupo, diferenciando-se dos outros componentes. Faz parte da natureza do grupo esse confronto entre individualismo e espírito coletivo.

Inicialmente, a criança faz parte do grupo familiar, no qual tem um lugar definido e aprende certas relações sociais. Depois, os grupos diversificam-se à medida que a criança "se torna mais livre nas suas ligações possíveis, mais polivalente nas suas relações com os outros, mais apta a combinar os seusactos com os de colaboradores eventuais" (Wallon, 1954/1975c, p. 178).

\section{Método}

A pesquisa, de abordagem qualitativa, teve a observação como instrumento metodológico, aceitando-se que esta não é uma cópia exata do fenômeno observado e que consiste em um recorte da realidade feito pelo pesquisador. "Não há observação sem escolha ou sem alguma relação implícita ou não. A escolha é dirigida pelas relações que possam existir entre o objeto ou o acontecimento e nossa expectativa..." (Wallon, 1941/2007, p. 17). Também se considerou a afirmação de Wallon (1937/1975d) de que, para conhecer o comportamento da criança, é imprescindível observá-la em seu meio, em diferentes atividades cotidianas, particularmente na escola.

A observação permite um contato estreito entre o pesquisador e o fenômeno em estudo. Segundo Lüdke e André (1986), esse contato apresenta uma série de vantagens. Primeiramente, a experiência direta é a melhor forma de verificar a ocorrência de um fenômeno. Por meio da observação, o pesquisador aproxima-se da perspectiva do sujeito, podendo compreender melhor o significado que atribui à realidade circundante e às suas próprias ações. Também permite a coleta de dados em situações nas quais não é possível de outra forma - por exemplo, quando os sujeitos não podem ou não querem fornecer informações por meio de outros instrumentos, como entrevistas ou depoimentos. Outra vantagem é que como "principal instrumento da investigação, o observador pode recorrer aos conhecimentos e experiências pessoais como auxiliares no processo de compreensão e interpretação do fenômeno estudado" (Lüdke \& André, 1986, p. 26).
O trabalho de campo foi realizado durante o segundo semestre de 2011, em uma escola municipal da Zona Oeste de São Paulo, que atendia 690 alunos, distribuídos em dois turnos de funcionamento. O edifício escolar possuía dois andares em que se encontravam as salas de aula. No térreo, havia um pátio coberto,no qual estavam distribuídos algunsbebedouros, quatro mesas retangulares para as refeições, um pequeno palco com uma mesa e algumas estantes com revistas, além da cozinha e dos banheiros. Esse pátio dava acesso a uma área externa, onde havia um espaço semicircular ladeado por arquibancadas coloridas e duas quadras de tamanho não oficial. Ainda nessa área, havia um grande brinquedo de madeira no qual as crianças podiam subir, escorregar e se pendurar. Uma escadaria levava a uma quadra e a um pequeno parque, ambos utilizados também pela comunidade. Em um prédio anexo, funcionavam a Sala de Leitura e a Sala de Informática.

Duas turmas de $1^{\circ}$ ano, com 26 alunos cada, foram observadas em diferentes períodos dentro do turno escolar, com diferentes professores e em diferentes espaços. Os alunos do $1^{\circ} \mathrm{B}$ demonstravam envolvimento e interesse nas tarefas propostas, além de entrosamento entre eles e com a professora. Os alunos do $1^{\circ} \mathrm{C}$ eram, em sua maioria, muito agitados e não conseguiam se concentrar na realização das atividades. Ambas as professoras eram graduadas em Pedagogia e possuíam doze anos de experiência no magistério.

Durante as sessões de observação, distribuídas em quatro semanas consecutivas,eram anotadas palavras ou frases curtas que pudessem ajudar a recordar os eventos quando fosse redigir o diário de campo. O registro era feito no mesmo dia da sessão, conforme orientações de Bogdan e Biklen (1991/2010), evitando, assim, o esquecimento de fatos.

No início de cada registro, identificava-se cada sessão com a turma observada (B ou C), data e horário (início e término) e um número para indicar a ordem daquela sessão no total do estudo. O registro era descritivo, principalmente em relação ao comportamento e às atitudes dos alunos e dos professores. Ao longo do diário de campo, os sentimentos, as impressões, os problemas e as especulações do pesquisador foram registrados, sem, entretanto, misturá-los à descrição objetiva. Esse tipo de anotação era feita em parágrafo recuado e precedido pelas iniciais C.O. (comentários do observador). Terminada a fase de produção de informações, foi feita a leitura dos diários de campo, permitindo a retomada dos fatos observados e uma visão do todo.

Para sistematizar as informações, foi elaborado um quadro com quatro colunas: registro das observações, comentários do observador, eixos temáticos e teoria de apoio. A primeira coluna continha a descrição dos fatos observados, e a segunda, as observações do pesquisador. Tendo por base a psicogenética walloniana, na terceira coluna, foram registradas sugestões de eixos temáticos para discussão de cada cena ou episódio, e na quarta coluna, os conceitos teóricos que dariam suporte a essa discussão. 


\section{Resultados e discussão}

Em função dos dados coletados, surgiram quatro eixos temáticos: movimento e processo de ensino, espaço e movimento, movimento e representação, movimento e autodisciplina mental. Considerando que o foco da pesquisa era a dimensão motora, vale ressaltar que houve episódios que não corresponderam a nenhum dos eixos, pois apresentavam predomínio de outros conjuntos funcionais ou se relacionavam aos encaminhamentos dados pela professora para a realização das atividades.

\section{Movimento e processo de ensino}

A prática pedagógica apresenta duas dimensões fundamentais: o ensino de conteúdos e a gestão de classe. Para um trabalho bem sucedido, o professor precisa equilibrar essas duas tarefas. A observação evidenciou que o movimento, em sua função cinética, era um dos fatores que mais exigia a atenção do professor em relação à gestão da classe e que, consequentemente, influía na gestão do conteúdo. Situações em que alunos se arrastavam pelo chão ou corriam pela sala levavam a professora a interromper várias vezes a atividade proposta, o que acabava ocasionando uma diminuição do tempo dedicado ao ensino.

Apesar de a criança de seis anos apresentar certa acomodação motora, isso ainda é instável. Para conciliar essa necessidade de movimento, característica da idade, com o ensino de conteúdos,o professor pode planejar atividades que incluam movimento, o que pode ajudá-lo na gestão da classe e do conteúdo.

Certa vez, por exemplo, a professora do $1^{\circ} \mathrm{B}$ entregou uma calculadora a cada aluno e, após um período de exploração livre, solicitou que registrassem na máquina a idade de cada pessoa da sala. Isso exigiu que os alunos circulassem pelo espaço. Ao observar a classe naquele momento, o que se via era um fluxo ordenado. As crianças movimentavam-se com um objetivo a cumprir, não houve desentendimentos ou qualquer tipo de confusão. Terminada essa atividade, os alunos pareciam mais preparados para realizar outra que exigisse maior concentração.

Quanto ao movimento em sua função tônica, especificamente o movimento das reações posturais, cuja origem está na variação das emoções, muitas vezes passou despercebido pelo professor, pois não há deslocamentos do corpo, as mudanças são visíveis apenas na plástica da musculatura corporal. O fato de o professor lidar com muitas crianças ao mesmo tempo torna difícil captar todos os movimentos expressivos; porém, pode-se perceber alguns deles. Almeida (2004, p. 126) afirma que "o olhar, a tonicidade, o cansaço, a atenção, o interesse são indicadores do andamento do processo de ensino que [o professor] está oferecendo". Esses sinais podem auxiliar o professor a avaliar a aula ou atividade que está sendo desenvolvida e, caso seja necessário, dar-Ihe outro encaminhamento; ou, então, podem servir-Ihe para reflexões posteriores sobre sua prática pedagógica.

\section{Espaço e movimento}

O espaço influi no comportamento das crianças. Um espaço amplo é um convite ao movimento: correr, pular, rolar, arrastar-se, dar piruetas etc., ao passo que o espaço ocupado por mobiliário, por exemplo, restringe o movimento.

De acordo com Wallon (1935/1975f, p. 351), é preciso "viver o espaço dinamicamente e utilizá-lo geograficamente antes de sublimá-lo em esboços mais ou menos abstractos para os nossos diferentes sistemas de referência”, ou seja, o espaço mental, que permite operar com representações, procede da vivência do espaço geográfico.

É do espaço que depende a realização de uma ordem qualquer, inclusive na linguagem: ordem das sílabas na palavra, ordem das palavras na frase. Na categorização, ao separar uma coisa da outra, concreta ou mentalmente, também é preciso distribuí-las por lugares diferentes, em configurações que façam sentido (Wallon, 1941/2007).

É na interação da criança com o meio que a intuição espacial vai-se transformando em esquematização mental. Vale ressaltar que "a construção do espaço mental, condição para o desenvolvimento do pensamento, não está apenas ligada ao ato motor" (Prandini, 2004, p. 44), também depende da afetividade, donde podemos concluir que o processo de aprendizagem se realiza mediante a integração das dimensões motora, afetiva e cognitiva.

$\mathrm{Na}$ escola em que a pesquisa foi realizada, não havia brinquedos ou espaço apropriado para as crianças brincarem; entretanto, elas podiam acessar um pequeno parque público, localizado ao lado da escola. Cumpre observar que a maioria das escolas públicas municipais não apresentava espaços diferenciados para receber crianças de seis anos à época da implementação da lei.

\section{Movimento e representação}

Por meio do movimento, o ato se inscreve no momento presente, mas pode pertencer a dois planos diferentes. O movimento pode pertencer ao plano concreto, sendo o ato motor propriamente dito, ou pode pertencer ao plano da representação e do conhecimento, ao pressupor meios que não dependem das circunstâncias concretas nem da capacidade motora da pessoa (Wallon, 1941/2007).

A passagem entre 0 ato motor e a representação ocorre por meio da imitação. Esta se inicia quando a criança tem cerca de um ano e meio, vai passando por transformações e ainda pode ser encontrada nas crianças de seis anos.

Foram observados apenas dois episódios de imitação propriamente dita: um aluno imitando o Chaves (personagem de seriado mexicano) e outro imitando uma atitude da professora. O primeiro se trata da imitação de um modelo, objeto de admiração. Por meio da imitação, o menino 
reproduzia a fala e o comportamento da personagem, como se ele fosse o próprio Chaves, porém não se tratava de mero automatismo, havia o componente da invenção quando apresentava meneios e gestos próprios. Já no segundo episódio, o aluno estava explicando como resolvera determinado problema matemático e, como os outros alunos estivam desatentos, disse que teria de usar o microfone, recurso que a professora utilizava, de vez em quando, para obter a atenção da classe. Trata-se, então, de imitação refletida, que se integra ao comportamento: o intuito do aluno ao imitar a atitude da professora era obter o mesmo resultado que ela - a atenção dos alunos.

Os mais frequentes foram episódios envolvendo brincadeiras nas quais os gestos eram fundamentais. Tais brincadeiras, muitas vezes, ocorriam dentro da sala de aula e podem ser consideradas como um meio de a criança se desligar das atividades impostas. Nessa idade de seis ou sete anos, apesar de haver diferenças de pessoa para pessoa, a criança geralmente apresenta uma disciplina mental ainda frágil. Após um período de tempo, que varia de acordo com cada indivíduo, a criança não consegue manter sua atenção na atividade proposta e volta-se para outras atividades - nesse caso, para brincadeiras ficcionais ou de faz de conta.

Wallon (1941/2007, p. 63-64) afirma que com "a ficção introduz-se na vida mental o uso dos simulacros". O simulacro, prelúdio da representação, é um ato sem objeto real. Nas brincadeiras observadas, as crianças utilizavam lápis no lugar de espadas, caixas no lugar de armaduras, apontador no lugar de carrinho etc. Algumas vezes, há ausência de qualquer objeto e só o gesto é utilizado. Elas se divertem com a imaginação, por isso os brinquedos que mais lhe agradam são aqueles sobre os quais podem criar livremente.

A ideia de Wallon (1941/2007) de que o brincar se confunde com a própria atividade infantil enquanto esta permanece espontânea é corroborada pelos estudos de Matti Bergstrom e Pia Ikonen(conforme citado por Haddad \& Horn, 2011), pesquisadoras finlandesas que, em artigo publicado na revista Infância na Europa, apresentam uma abordagem do espaço sob a ótica do desenvolvimento neuropsíquico. De acordo com essas autoras, a ideia de que a brincadeira prepara a criança para a vida social leva os adultos a organizarem as atividades lúdicas reproduzindo o mundo lógico e ordenado deles; entretanto, é "a brincadeira livre que permite à criança penetrar no mundo dos possíveis e Ihe oferece a liberdade necessária ao seu desenvolvimento cerebral" (Haddad \& Horn, 2011, p. 49-50).

De fato, houve poucos episódios envolvendo brincadeiras espontâneas; geralmente, eram dirigidas ou propostas pela professora. Em um desses episódios, um menino subiu nas arquibancadas e começou a brincar com outro, imaginandoque escalava o Everest e que possuía superpoderes como voar e agir sobre o ferro. O pensamento permite infinitas possibilidades e é por meio da linguagem oral - e nessa idade ainda por gestos - que ele se expressa e se faz conhecer.
De acordo com Wallon(1941/2007, p. 157-158),"como os mecanismos da ação são ativados antes dos da reflexão, quando [a criança] quer imaginar uma situação não consegue fazê-lo se antes não se envolver de alguma forma com ela por meio de gestos". À medida que a representação evolui, necessita menos do movimento. Este, em sua dimensão cinética, tende a diminuir, dando lugar ao ato mental.A evolução da linguagem possibilitará o fortalecimento da representação e, consequentemente, do pensamento.

\section{Movimento e autodisciplina mental}

A atenção, denominada por Wallon de autodisciplina mental, é uma capacidade que se desenvolve por volta dos seis anos e possibilita que a criança permaneça mais tempo voltada para uma mesma atividade, desconsiderando estímulos ambientais que não estejam relacionados a tal atividade. Isso é possível graças à maturação dos centros nervosos de discriminação e de inibição, bem como pela influência do meio social.

Nos grupos observados, havia crianças que realizavam outra atividade ou manipulavam algum objeto enquanto a professora desenvolvia uma atividade oral. À primeira vista, poderíamos julgá-las desatentas, pois tendemos a considerar atentas aquelas que focalizam o olhar na pessoa que está falando ou executando alguma ação - nesse caso, a professora. Entretanto, quando esta lançava uma pergunta para a turma, várias dessas crianças respondiam prontamente.

Por outro lado, havia crianças que não conseguiam se desligar da atividade a que se dedicavam para realizar a atividade proposta pela professora. Outras, ainda, não conseguiam fixar sua atenção em nenhuma atividade. No primeiro caso, trata-se de perseveração; e no segundo, de instabilidade, ambas expressões da inércia mental, em que a criança não possui controle sobre suas ocupações, não sendo capaz de mudá-las ou de se fixar nelas. Isso ocorre porque a autodisciplina mental ainda não se desenvolveu plenamente. Segundo Wallon (1941/2007), somente entre dez e treze anos é que a perseveração e a instabilidade diminuem, a criança passa a ser capaz de permanecer por mais tempo em uma mesma atividade e a depender menos dos símbolos concretos, e seu pensamento se torna mais capaz de abstração.

Concorrem para o desenvolvimento da atenção e do controle do movimento tanto a maturação orgânica quanto a aprendizagem. À escola, na figura do professor, cabe assegurar que o aluno assimile as noções que não poderiam ser adquiridas espontaneamente, isto é, que dependem de ensino. Para Wallon(1929/1975a, p. 370),"a grande dificuldade e o paradoxo do ensino é ter de desviar a criança da sua experiência imediata e espontânea para a interessar por aquilo que não se relaciona directamente com as suas necessidades ou desejos actuais".

Considerando que o interesse é o principal estímulo da atenção, o professor pode, a partir de objetos ou situações 
que interessem às crianças, fazê-las descobrir o que se relaciona com esses interesses, ampliando seus conhecimentos e relacionando-os com o universo objetivo. Quando a tarefa se mostra interessante, o aluno é capaz de se dedicar por mais tempo a ela. $\mathrm{O}$ interesse "exprime-se na actividade e na curiosidade espontânea da criança. A partir de objectos ou de situações que a tocam de perto, é necessário fazê-la descobrir, gradualmente, o que também de perto se relaciona com seus interesses"(1929/1975a, p. 370).

\section{Considerações finais}

As relações entre o ser vivo e o meio são de dependência e de transformações mútuas. A escola é tanto um meio físico e de ação, como um meio funcional, ou seja, possui uma função específica: instruir as crianças e colocá-las em contato com novas formas de organização e de relações grupais. Apesar de muitas das crianças de seis anos haverem frequentado anteriormente escolas de educação infantil, o ensino fundamental configura-se de forma diferente, tanto em relação aos objetivos e à organização espacial quanto às relações interpessoais.

A função do ensino fundamental é garantir o contato sistemático da criança com a cultura acumulada pela humanidade, fornecendo-lhe instrumentos para compreender e agir sobre os diferentes meios. Por volta de seis anos, idade de ingresso no ensino fundamental, a criança encontra-se em processo de maturação psicobiológica e a escola"atua como estímulo nesse processo de maturação, para dar forma e conteúdo às condutas intelectuais e sociais" (Zazzo, 1956/1975, p. 369-370, tradução nossa).

Nessa fase, a criança tem grande necessidade de movimento, pois é por meio dele que ela vive dinamicamente o espaço, e é essa vivência do espaço físico que irá possibilitar o desenvolvimento do espaço mental. Para tanto, é preciso que as escolas ofereçam espaços adequados, o que nem sempre acontece. A forma como o espaço é concebido e organizado interfere na aprendizagem, estimulando-a ou limitando-a. De acordo com Horn (2004), nas escolas municipais infantis da Reggio Emilia, região do norte da Itália, o espaço é visto como um elemento curricular planejado para facilitar a interação entre crianças e objetos e das crianças entre si, favorecendo, portanto, a aprendizagem. Além disso, toda a comunidade escolar discute e planeja como os espaços serão estruturados. No município de São Paulo, o espaço faz parte do conteúdo curricular, especialmente de Matemática e Geografia, porém apenas como conteúdo, já que a escola não pensa no espaço como facilitador da aprendizagem.

A motricidade não pode ser apenas parte do currículo de Educação Física. Enquanto a função simbólica não se estabelece, o gesto é fundamental na expressão da criança. O movimento deveria ser contemplado nos planejamentos de todas as disciplinas, principalmente nos anos iniciais do ensino fundamental, inclusive porque a integração do movimento às atividades possibilitaria uma gestão mais tranquila da classe. Além da necessidade de movimento, a falta de atenção e de concentração também são características da criança de seis anos, decorrentes da maturação dos centros nervosos de inibição e de discriminação que ainda não se completou. Sabendo disso, o professor pode planejar atividades que envolvam movimento, com duração mais curta ou que exijam mais atenção intercaladas com atividades que impliquem em movimento, para ir, aos poucos, ampliando esse período de exigência de concentração e atenção.

As brincadeiras não dirigidas também são importantes para o desenvolvimento das funções motoras e para o exercício da função simbólica que está despontando. Segundo Garanhani (2004, p.29), "é no brincar que a criança adapta a sua condição físico-motora e a do objeto e/ou situação às condições exigidas pela ação e, consequentemente, ela consegue experimentar, explorar e compreender os significados do meio". Apesar da significativa produção teórica que afirma a importância da brincadeira nos processos de desenvolvimento e de aprendizagem, na prática persiste a ideia de que o brincar é uma atividade paralela e menos importante no contexto da formação escolar da criança (Ministério da Educação e Cultura, Secretaria de Educação, 2007). Isso é corroborado por Oliveira (2010), que, em sua pesquisa, verificou que o discurso dos professores de educação infantil já incorporou o conceito de movimento proposto por Wallon, que aparece nos documentos curriculares; entretanto, o mesmo não aconteceu em relação à prática. "Assim, a ideia de que linguagem, cultura e movimento são elementos imbricados e indissociáveis, ainda passa longe do cotidiano das instituições", afirma Oliveira (2010, p.114).

Nosso objetivo ao apresentar um recorte da investigação empreendida foi evidenciar a necessidade de alertar gestores e professores para a importância de se problematizar a questão do movimento quando sãoplanejadas e executadas atividades curriculares. Conhecendo o desenvolvimento infantil, o professor do $1^{\circ}$ ano pode ser mais tolerante em relação a certas atitudes da criança que ainda independem de sua vontade, como a desatenção e a movimentação. A escola tem uma grande responsabilidade sobrecada criança que nela ingressa: instrumentalizá-la com os elementos culturais e linguísticos, favorecendo o avanço da função simbólica e do pensamento categorial, e, consequentemente, o refinamento dos gestos e a transformação do ato motor em ato mental.

\section{Referências}

Almeida, L. R. (2004). Ser professor: um diálogo com Henri Wallon. Em A. A. Mahoney \& L. R. Almeida (Orgs.), A constituição da pessoa na proposta de Henri Wallon (pp. 119-140). São Paulo: Edições Loyola.

Almeida, L. R. (2010). Cognição, corpo e afeto. Educação: história da pedagogia, (3), 20-23.

Bogdan, R. \& Biklen, S. (2010). Investigação qualitativa em educação 
(M.J. Alvarez, S.B. dos Santos \& T.M. Baptista, Trad.) Porto: Porto Editora. (Trabalho original publicado em 1991)

Garanhani, M. C. (2004). Concepções e práticas pedagógicas de educadoras da pequena infância: os saberes sobre o movimento corporal da criança. Tese de Doutorado, Pontifícia Universidade Católica, São Paulo-SP.

Gauthier, C. \& Martineau, S. (2001). Triângulo didático-pedagógico: o triângulo que pode ser visto como um quadrado. Educação nas Ciências, 1 (1), 46-77.

Guillaume, P. (1975). Los aspectos afectivos de laimitacion. Em J. Leif \& P. Juif (Orgs.), Textos de psicologia delniño y del adolescente (pp 230-231). Madrid: Narcea. (Trabalho original publicado em 1950)

Haddad, L. \& Horn, M. G. S. (2011). Criança quer mais do que espaço. Educação: educação infantil, (1), 42-59.

Horn, M. G. S. (2004). Sabores, cores, sons, aromas: a organização dos espaços na educação infantil. Porto Alegre: Artmed.

Lüdke, M. \& André, M. E. D. A. (1986). Pesquisa em educação: abordagens qualitativas. São Paulo: EPU.

Mahoney, A. A. (2009). Introdução. Em A. A. Mahoney \& L. R. Almeida (Orgs.), Henri Wallon: psicologia e educação (pp 9-18). São Paulo: Edições Loyola.

Ministério da Educação e Cultura, Secretaria de Educação Básica (2007). Ensino fundamental de nove anos: orientações para a inclusão da criança de seis anos de idade. Brasília: Ministério da Educação e Cultura, Secretaria de Educação Básica.

Oliveira, N. R. C. (2010). Corpo e movimento na educação física: concepções e saberes docentes que permeiam as práticas cotidianas. Tese de Doutorado, Universidade de São Paulo, São Paulo-SP.

Prandini, R. C. A. R. (2004). A constituição da pessoa: integração funcional. Em A. A. Mahoney \& L. R. Almeida (Orgs.), A constituição da pessoa na proposta de Henri Wallon (pp 25-46). São Paulo: Edições Loyola.

Tran-Thong (1987). Estádios e conceito de estádio de desenvolvimento da criança na psicologia contemporânea. (Maia, M, Trad.) Porto: Edições Afrontamento. (Trabalho original publicado em 1967).

Wallon, H. (1975a). As causas psicofisiológicas da desatenção na criança. Em H. Wallon, Psicologia e educação da infância (Rabaça, A., Trad.) (pp. 367-378). Lisboa: Editorial Estampa.
(Trabalho original publicado em 1929, no Bulletin de la Société Française de Pédagogie $n^{\circ} 32$ ).

Wallon, H. (1975b). A importância do movimento no desenvolvimento psicológico da criança. Em H. Wallon, Psicologia e educação da infância (Rabaça, A., Trad.) (pp. 75-82). Lisboa: Editorial Estampa. (Trabalho original publicado em 1956, em Enfance $n^{\circ} 2$ ).

Wallon, H. (1975c). Os meios, os grupos e a psicogênese da criança. Em H. Wallon, Psicologia e educação da infância. (Rabaça, A., Trad.) (pp. 163-179) Lisboa: Editorial Estampa. (Trabalho original publicado em 1954, em CahiersInternacionaux de Sociologie).

Wallon, H. (1975d). Psicologia e educação da infância. Em H. Wallon, Psicologia e educação da infância (Rabaça, A., Trad.) (pp. 9-21). Lisboa: Editorial Estampa. (Trabalho original apresentado em 1937).

Wallon, H. (1975e). A psicologia genética. Em H. Wallon, Psicologia e educação da infância (Rabaça, A., Trad.) (pp. 53-72) Lisboa: Editorial Estampa. (Trabalho original publicado em 1956, no Bulletin de Psychologie $\left.n^{\circ} 1\right)$.

Wallon, H. (1975f). O real e o mental. Em H. Wallon, Psicologia e educação da infância (Rabaça, A., Trad.) (pp 297-351). Lisboa: Editorial Estampa. (Trabalho original publicado em 1935, no Journal de Psychologie, a. XXXI, n. 5-6).

Wallon, H. (2007). A evolução psicológica da criança (Berliner, C., Trad). São Paulo: Martins Fontes. (Trabalho original publicado em 1941).

Wallon, H. (2008). Do ato ao pensamento: ensaio de psicologia comparada (Titton, G.A., Trad.) Petropólis: Vozes. (Trabalho original publicado em 1942).

Zazzo, R. (1975). El niño de seis años. Em J. Leif \& P. Juif (Orgs.), Textos de psicologia del niño y del adolescente (pp. 369-371). Madrid: Narcea. (Trabalho original publicado em 1956).

Zazzo, R. (1976). Psicologia y marxismo: La vida y La obra de Henri Wallon. Madrid: Pablo Del Rio. (Trabalho original publicado em 1975).
Recebido em: 01 de fevereiro de 2016 Aprovado em: 16 de janeiro de 2017 


\section{Sobre as autoras:}

Fátima Bissoto Medeiros Cintra (fbissoto@gmail.com)

Mestrado em Educação (Psicologia da Educação) pela Pontifícia Universidade Católica de São Paulo (2012), docente da Prefeitura Municipal de São Paulo.

Laurinda Ramalho Almeida (laurinda@pucsp.br)

Doutorado em Psicologia da Educação pela Pontifícia Universidade Católica de São Paulo, Brasil (1992),Docente do Programa de Estudos PósGraduados em Educação: Psicologia da Educação e Vice-Coordenadora do Mestrado Profissional em Educação: Formação de Formadores, ambos da Pontifícia Universidade Católica de São Paulo. 